\title{
Socio-Economical Impact Assessment of Drought on the Rural Agriculture; a Case Study of Rural Districtin Southern Iran
}

\author{
Sirous Ghanbari, Habib Bayad, Somayeh Rezayi \\ Department of Geography and Rural Planning, University of Sistan and Baluchestan, Zahedan, Iran
}

Email address:

ghanbari@gep.usb.ac.ir(S. Ghanbari), habib.bayad@yahoo.com (H. Bayad), s_rezayi2012@yahoo.com (S. Rezayi)

To cite this article:

Sirous Ghanbari, Habib Bayad, Somayeh Rezayi. Socio-Economical Impact Assessment of Drought on the Rural Agriculture; a Case Study of Rural District in Southern Iran. International Journal of Environmental Protection and Policy. Vol. 3, No. 2, 2015, pp. 53-56.

doi: 10.11648/j.ijepp.20150302.14

\begin{abstract}
This study has aimed to assess the social and economic impacts of drought on agriculture of a rural district in southern Iran entitled Jiroft County. To prepare data, about 217 questionnaire forms were collected in the field works during 2011-2012 then statistically analyzed. According to drought time series of the study area, the year 2008 is known as a strongest drought, which has effected on job sharing, income rate and cultivated areas. The impacts of drought on agricultural workforces and migration are approximately negligible, while the changes on job condition after drought are temporarily high $(\mathrm{P}<0.01)$. The correlation analysis exhibited a positive meaningful relation between drought effect and economic income. Income of household from agricultural activities has been remarkable declined hence the rate of investment on agricultural section has been reduced. The changes in household income, cultivated areas and agricultural employment have leaded the various migrations in recent years. About $30 \%$ of the population has migrated out of the study area after the 2008 drought event. Due to the migration of $\sim 1100$ populations with mean monthly income of $\sim 30$ USD, the volume of $\sim 400,000$ USD have been lost annually after the 2008 drought event in the study area.
\end{abstract}

Keywords: Drought, Agriculture, Rural Household Income, Social and Economical Impact Assessment, Cultivated Areas, Jiroft County, Southern Iran

\section{Introduction}

Drought event as a main natural hazard is characterized by multiple climatological, hydrological and agricultural parameters [1]. Drought is an insidious, slow-onset natural hazard that produces a complex web of impacts that ripple through many sectors of the economy [2]. Agricultural drought is a powerful natural force shaping significant impacts on food security and cropland resources [3]. A number of studies have been carried out on the impact of droughts on agriculture [4], [5] and the temporal and spatial patterns of drought but few studies have been done on the issue of drought hazard assessment. In recent years, severe and extensive droughts in many parts of the world have resulted in food insecurity, loss of social life and negative economic impacts [6], [7].Any contribution to understand and predict drought conditions will be a step toward minimizing drought impacts. Assessing the effects of extreme droughts on agriculture might help to properly anticipate and adapt farming to maximize agricultural production [8],[9], [5]. In this regard, the probability of drought occurrences reflects the impact of drought hazard on the agricultural productions [10].A drought event today may be of similar intensity and duration as a historical drought event, but the impacts will likely differ markedly because of changes in societal and economical characteristics [2]. In the arid and semi-arid regions, droughts happened frequently and their impacts are magnified by deep rural poverty, limited government capacity, exposure to additional political, economic, and health shocks [11]. Economical impacts of drought are categorized as high expenses of agricultural products and low efficiency of food products. As well as, the social effects of drought are categorized as declined in water resources, food security and mitigation measures [12]. A comprehensive assessment of the impacts of drought on socio-economic structures has been revealed that the deepen impacts on the agricultural activities in the developing world [13].For agricultural households in the developing world, drought is an important negative shock 
that can weaken incomes and well-being. In the arid and semi-arid regions of the Middle East, drought hazard leads to loss of income and forced migrations [14]. As a drought prone area in the Middle East, Iran has currently launched a crisis management approach to mitigate the harmful impacts of drought [15]. The impact of drought hazard in Iran as an arid and semi-arid region is very important in agricultural productions and their consequences can be applied to the future strategic planning in crop production schemes [10]. According to drought time series of synoptic station, the year 2008 is known as a strongest drought over the study area. The extent of drought impacts on 2008 in southern Iran especially in rural district of Jiroft County has remarkable declined the agricultural products and annual economical income of rural households. The main aim in the present study was to assess the socio-economical impacts of a drought event on a rural agriculture in southern Iran.

\section{Methodology}

\subsection{Study Area}

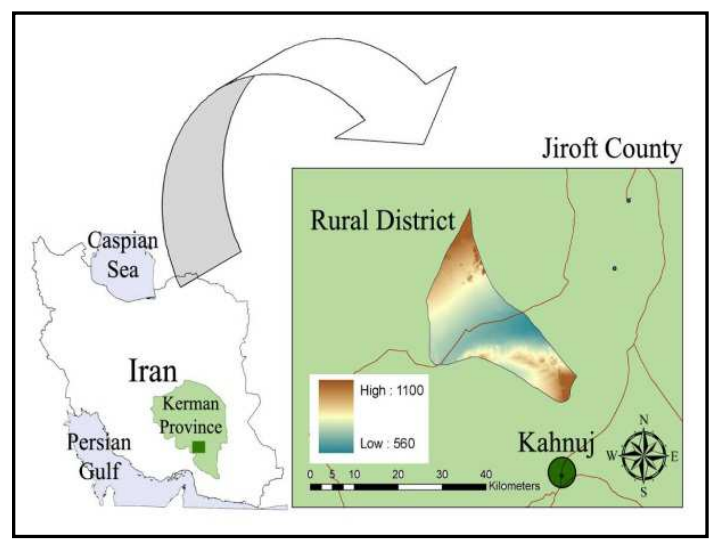

Figure 1. The geographical position of the study area in southern Iran.

According to the latest division of the country, the study area of rural district is in Jiroft County, Kerman Province. This region with a total area of $470 \mathrm{~km}^{2}$, lies between $57^{\circ} 25^{\prime}-57^{\circ} 45^{\prime}$ Eastern longitude and $28^{\circ} 05^{\prime}-28^{\circ} 25^{\prime}$ Northern latitude at the south west of Middle East. The population of this rural district has been decreased within 2005-2010 time-period from 3367 to 2270 . The study area averagely is located on elevation ranges between 560 and 1100 a.s.l (Fig. 1). According to the climatologic data of Kahnuj synoptic station, the annual precipitation and mean annual temperature in this region were estimated about $26^{\circ} \mathrm{C}$ and $180 \mathrm{~mm}$, respectively within 2005-2014 (http://www.irimo.ir) [16].

\subsection{Data Analysis}

In the present study, the statistical analysis to gather with the field work operations was applied. Standardized evaluation of the precipitation data based on the $\mathrm{z}$-index values revealed the year 2008 as the strongest drought in the last decade. According to table 1, drought events continually occurred during 2006-2008, while the drought event for year 2008 was the strongest with index value of -1.26 . In this year the annual precipitation of the study area has been recorded as $94.3 \mathrm{~mm}$, which is twice lesser than of mean value. In order to identify the economic and social impacts of this drought event on rural settlements about 17 indicators were identified in table 2, which were reflected in 217 questionnaires as the main tool in the fieldwork. Based on Cochran procedure, about 217 household questionnaire forms were distributed in rural district by random sampling method. All of the responses after the Wilcoxon statistical tests in SPSS were used to assess the indicator differences before and after drought. Wilcoxon test, suggests significant difference among indicators before and after drought event with meaningful level less than 0.05 (Table 2 ). The result revealed the relation of drought impact on socio-economic levels. Hence, to examine the statistical relationships between drought impacts, rural incomes, cultivated areas and agricultural employments the "Kendall tai eBay" correlation coefficient was used.

Table 1. Drought events in the study area within the last decade.

\begin{tabular}{llll}
\hline year & Precipitation $(\mathbf{m m})$ & z-index & explain \\
\hline 2005 & 280.5 & 1.84 & - \\
2006 & 112.1 & -0.97 & drought \\
2007 & 152.4 & -0.29 & drought \\
2008 & 94.3 & -1.26 & drought \\
2009 & 209.8 & 0.66 & - \\
2010 & 150.3 & -0.33 & drought \\
2011 & 197.4 & 0.46 & - \\
2012 & 95.6 & -1.24 & drought \\
2013 & 195.6 & 0.43 & - \\
2014 & 210.8 & 0.68 & - \\
\hline
\end{tabular}

Table 2. Results from statistical analysis of differences between drought impacts before and after the drought of 2008 based on Wilcoxon test.

\begin{tabular}{|c|c|c|c|c|c|c|}
\hline \multirow{2}{*}{ Level } & \multirow{2}{*}{ Indicator } & \multicolumn{2}{|l|}{ Ranks } & \multicolumn{3}{|c|}{ Test Statistics } \\
\hline & & Positive & Negative & Equal & $\mathbf{Z}$ & Mean. level \\
\hline \multirow{10}{*}{ Economic } & Reduction of production inputs & 195 & 0 & 22 & 10.583 & 0.000 \\
\hline & Revenue decline of agricultural products & 162 & 10 & 45 & 10.765 & 0.000 \\
\hline & Revenue decline of livestock production & 173 & 9 & 35 & 10.795 & 0.000 \\
\hline & Less employment in the village & 167 & 15 & 35 & 10.850 & 0.000 \\
\hline & Reduction of performance of farms & 198 & 0 & 19 & 10.431 & 0.000 \\
\hline & Reduction of crop yields & 204 & 0 & 13 & 10.626 & 0.000 \\
\hline & Reduction of gardens & 194 & 0 & 23 & 10.340 & 0.000 \\
\hline & Decrease in current $\&$ fixed assets of rural households & 165 & 0 & 40 & 10.505 & 0.000 \\
\hline & Decrease in values of rural households possessions & 147 & 30 & 40 & 10.660 & 0.000 \\
\hline & Decrease in wages for daily wage jobs & 120 & 26 & 71 & 4.245 & 0.000 \\
\hline
\end{tabular}




\begin{tabular}{|c|c|c|c|c|c|c|}
\hline \multirow{2}{*}{ Level } & \multirow{2}{*}{ Indicator } & \multicolumn{2}{|l|}{ Ranks } & \multicolumn{3}{|c|}{ Test Statistics } \\
\hline & & Positive & Negative & Equal & $\mathbf{Z}$ & Mean. level \\
\hline & Increase in the price of manufacturing organizations & 175 & 18 & 24 & 10.924 & 0.000 \\
\hline \multirow{6}{*}{ Social } & Less motivation of rural to invest in livestock sector & 162 & 25 & 30 & 11.109 & 0.000 \\
\hline & Loss of self- confidence & 168 & 22 & 27 & 10.929 & 0.000 \\
\hline & Smuggling of product \& fuel & 80 & 43 & 94 & 0.323 & 0.742 \\
\hline & Having stress & 181 & 10 & 26 & 10.672 & 0.000 \\
\hline & Conflict among farmers & 162 & 200 & 35 & 11.299 & 0.000 \\
\hline & Training problems & 163 & 0 & 54 & 11.173 & 0.000 \\
\hline
\end{tabular}

\section{Results and Discussion}

Tables (3-5) presented the distribution of monthly rural incomes of households, cultivated areas and employments before and after the 2008 drought. Monthly rural income of household after drought significantly has been decreased $(\mathrm{P}<0.01)$. The main decrease was observed for incomes over than 30 US dollars for each household (13\%). Therefore, after drought period the cultivated areas have been reduced. The main reduction was observed for areas over than 1 hectare for each household (25\%). The changes of employments under the drought impacts of 2008 revealed a significant reduction in agricultural employments equal $43 \%$. This economic impact can be lead to the other socio-economic indicators in the rural district such as the reduction of crop production yields. Furthermore, findings of Kendall tai eBay test show a meaningful relation between decline of income, cultivated areas and agricultural employment before and after drought (Table 6).Between the Kendall eBay factors, the main impact of drought hazard of 2008 is observed on the cultivated areas variations with statistic of 1.68. In this regard, the vegetated and cultivated land degradation influenced by climatic extremes and drought events have been previously reported by [17], [18]. Also in accordant with [11], the migration consequences of drought event in the study area cannot represent a clear direct or indirect relationship with drought. Hence, the undesirable social and economic impacts in the region require the careful and long-term plans. Hence, drought hazards assessment is essential for making mitigation plans to reduce the social and economical impacts of drought.

Table 3. Distribution of monthly income of households before and after drought of 2008.

\begin{tabular}{lllll}
\hline $\begin{array}{l}\text { Monthly rural income of } \\
\text { household }\end{array}$ & $<\mathbf{3 0}$ USD & $>\mathbf{3 0}$ USD & Sum \\
\hline 2005 & frequency & 120 & 97 & 217 \\
(before drought) & $\%$ & 55 & 45 & 100 \\
2010 & frequency & 148 & 69 & 217 \\
(after drought) & $\%$ & 68 & 32 & 100 \\
\hline
\end{tabular}

Table 4. Distribution of cultivated areas of households before and after drought of 2008 .

\begin{tabular}{lllll}
\hline Cultivated areas of household & $<\mathbf{1 ~ H a}$ & $>\mathbf{1 ~ H a}$ & Sum \\
\hline 2005 & frequency & 140 & 77 & 217 \\
(before drought) & $\%$ & 65 & 35 & 100 \\
2010 & frequency & 196 & 21 & 217 \\
(after drought) & $\%$ & 90 & 10 & 100 \\
\hline
\end{tabular}

Table 5. Distribution of agricultural employees in households before and after drought of 2008.

\begin{tabular}{lllll}
\hline Employments of household & Agriculture & $\begin{array}{l}\text { Other/ } \\
\text { Unemployment }\end{array}$ & Sum \\
\hline 2005 & frequency & 135 & 82 & 217 \\
(before drought) & $\%$ & 63 & 37 & 100 \\
2010 & frequency & 44 & 173 & 217 \\
(after drought) & $\%$ & 20 & 80 & 100 \\
\hline
\end{tabular}

Table 6. Results of correlations between rural income, cultivated areas and agricultural employment before and after drought of 2008.

\begin{tabular}{llll}
\hline Kendall eBay factors & $\begin{array}{l}\text { Value of } \\
\text { statistic }\end{array}$ & $\begin{array}{l}\text { Significance } \\
\text { level }\end{array}$ & $\begin{array}{l}\text { Standard } \\
\text { deviation }\end{array}$ \\
\hline Rural income & 1.14 & 0.00 & 0.1 \\
Cultivated areas & 1.68 & 0.01 & 0.1 \\
Agricultural employment & 1.17 & 0.01 & 0.1 \\
\hline
\end{tabular}

Based on the results, we can claim that the drought impacts have clearly changed the economic and social conditions of the rural environment. In this regard, we observed that drought impacts on 2008 obviously have decreased the rural income, cultivated areas and agricultural employments in the study area $(\mathrm{P}<0.01)$. Drought event on 2008 influenced on the economic environment after the meteorological and hydrological droughts, which have been happened during 2006-2007 with lesser precipitation values.

\section{Conclusions}

Drought and low rainfall in recent years have diminished water resources required for agriculture and accordingly there has been depression in activities required for economy in the study area. Findings from the fieldwork show that impacts of drought in rural district from 2005 to 2010 have influenced various levels of rural household life. One of the most important impacts in the region is economical effect that has lead to the reduction in monthly income, cultivated areas and agricultural employment. According to the results, there is a meaningful relation between drought impact and mentioned indicators. The rural household incomes over than 30 US Dollars have been decreased after the 2008 drought event. Among 217 sampling study in fieldwork, about 56 households (25\%) have abandoned the cultivated areas over than 1 Hectare after the 2008 drought. The changes in household income, cultivated areas and agricultural employment have leaded the various migrations in recent years. In this regard, the population of the study area has been decreased within 2005-2010 time-period from 3367 to 2270. In other word, 
about $30 \%$ of the population has migrated out of the study area after the 2008 drought event. Due to the migration of $\sim 1100$ populations with mean monthly income of $\sim 30$ USD, the volume of $\sim 400,000$ USD have been lost annually after the 2008 drought event in the study area.

\section{Recommendations}

Based on findings some strategies and solutions are given to reduce the social and economic effects of drought as follows: Avoid of digging deep wells and abuse of under-ground resources as well as developing pressurized irrigation, Mechanization of agricultural systems for optimum cultivations and productions, Developing greenhouse plants by considering climate change, Cultivating drought tolerant plants and use of shallow ornamental plants consistent with climatic drought, Saving water by conventional systems of rainwater catchment levels, Application of FAO indicator of Agriculture Stress Index (ASI) to assess of drought event on agriculture (http://www.fao.org/giews/earthobservation) [19].

\section{Acknowledgements}

We are grateful to Dr. Mohammad Reza Mansouri Daneshvar for superior recommendations and technical annotations.

\section{References}

[1] Mishra AK, Singh VP (2010). A review of drought concepts. Journal of Hydrology 391: 202-216.

[2] Wilhite DA, Svoboda MD, Hayes MJ (2007). Understanding the complex impacts of drought: A key to enhancing drought mitigation and preparedness. Water Resour Manage 21:763-774.

[3] Qin Z, Tang H, Li W, Zhang H, Zhao S, Wang Q (2014). Modelling impact of agro-drought on grain production in china. International journal of Disaster Risk Reduction 7: 109-121.

[4] Wu J, He B, Lu A, Zhou L, Liu M, Zhao L (2011). Quantitative assessment and spatial characteristics analysis of agricultural drought vulnerability in China. Nat Hazards, 56(3): 785-801.

[5] Potop V (2011). Evolution of drought severity and its impact on corn in the Republic of Moldova. Theor Appl Climatol 105(3-4): 469-483.
[6] Blunden J, Arndt DS (2012) State of the climate in 2011. Bull. Amer. Meteor. Soc. 93: S1-S280.

[7] Grigg NS (2014) The 2011-2012 drought in the United States: New lessons from a record event. Int. J. Water Resour. Dev. 30: 189-199.

[8] Liu WT, Kogan FN (1996). Monitoring regional drought using the vegetation condition index. Int $\mathrm{J}$ Remote Sens. 17: 2761-2782.

[9] Calderini D, Slafer G (1998). Changes in yield and yield stability in wheat during the 20th century. Field Crops Res. 57: 335-347.

[10] Mansouri Daneshvar MR, Bagherzadeh A, Khosravi M (2013). Assessment of drought hazard impact on wheat cultivation using standardized precipitation index in Iran. Arabian Journal of Geosciences 6(11): 4463-4473.

[11] Gray C, Mueller V (2012). Drought and population mobility in rural Ethiopia. World Development 40(1): 134-145.

[12] Udmale PD, Ichikawa Y, Kiem AS, Panda SN (2014). Drought Impacts and Adaptation Strategies for Agriculture and Rural Livelihood in the Maharashtra State of India. The Open Agriculture Journal 8(1): 41-47.

[13] Fischer G, Shah M, Tubiello FN, Van Velhuizen (2005). Socio-economic and climate change impacts on agriculture: an integrated assessment, 1990-2080. Phil. Trans. R. Soc. B 360: 2067-2083.

[14] El-Kharraz J, El-Sadek A, Ghaffour N, Mino E (2012). Water scarcity and drought in WANA countries. Procedia Engineering $33: 14-29$

[15] Zarafshani K, Sharafi L, Azadi H, Hosseineininia G, De Maeyer P, Witlux F(2012). Drought Vulnerability assessment: The case of wheat farmers in western Iran. Global and Planetary Change 98: 122-130.

[16] Iranian Meteorological Organization (2014). http://www.irimo.ir.

[17] Pereira MG, Malamud BD, Trigo RM, Alves PI (2011). The history and characteristics of the 1980-2005 Portuguese rural fire database, Nat. Hazards Earth Syst. Sci. 11: 3343-3358.

[18] Combs S (2012). The impact of the 2011 drought and beyond. Texas Comptroller of Public Accounts Special Rep., Publ. 96-1704, $16 \mathrm{pp}$.

[19] Food and Agriculture Organization of the United Nations (2014). http://www.fao.org/giews/earthobservation. 